\title{
HUBUNGAN KEJADIAN FLAT FOOT TERHADAP KESEIMBANGAN DINAMIS PADA PELAJAR DI SMAN 3 MALANG
}

\author{
Fentikasari Setyaningrahayu*, Safun Rahmanto, Ali Multazam \\ Departement Fisioterapi, Universitas Muhammadiyah Malang, Jalan Bandung No. 1Malang 65133 \\ *Corresponding author: sarifentika@gmail.com
}

\begin{abstract}
ABSTRAK
Aktivitas di usia remaja menjdikan tubuh perlu pondasi yang kuat. Sebagai pondasi tubuh, kaki memiliki bagian penting bernama archus. Peran archus adalah memberikan kekuatan dan keseimbangan serta mendistribusikan berat badan secara merata pada kaki. Keseimbangan juga diperlukan oleh tubuh saat beraktivitas. Flat foot merupakan salah satu permasalahan archus. Berbagai permasalahan yang muncul akibat flat foot antara lain nyeri, meningkatnya risiko cedera, gangguan keseimbangan, dan deformitas berlanjut apabila tidak mendapat penanganan yang tepat. Penelitian ini bertujuan untuk mengetahui hubungan kejadian flat foot terhadap keseimbangan dinamis pada pelajar di SMAN 3 Malang. Penelitian ini bersifat observsional dengan pendekatan cross-sectional. 26 responden dalam penelitian ini diambil menggunakan teknik purposive sampling. Instrumen dalam penelitian ini menggunakan Staheli Arch Index untuk mengidentifikasi flat foot dan $Y$-Balance Test untuk mengukur keseimbangan dinamis. Uji Spearman digunakan untuk analisa data penelitian. Uji Spearman menunjukkan hasil nilai sig. 2 tailed keseimbangan dinamis kaki kanan = 0,104 dan kaki kiri = 0,197 dengan nilai $\alpha$ 0,05 yang bermakna H0 diterima. Tidak ada hubungan kejadian flat foot terhadap keseimbangan dinamis pada pelajar di SMAN 3 Malang.
\end{abstract}

Keywords: Flat foot, keseimbangan dinamis, remaja.

\section{PENDAHULUAN}

$\begin{array}{ccr}\text { Masa } & \text { remaja adalah periode } \\ \text { terjadinya } & \text { pertumbuhan } & \text { dan }\end{array}$ perkembangan secara fisik, psikologis, dan intelektual. Menurut Badan Kependudukan dan Keluarga Berencana (BKKBN),usia remaja adalah 10-24 tahun dan belum menikah (Depkes, 2017). Ketika remaja umumnya seseorang menjadi lebih aktif. Olahraga merupakan salah satu aktivitas fisik yang umum dilakukan oleh remaja (Damayanti, 2016). Gerakan seperti berjalan, berlari, melompat ketika berolahraga melibatkan kaki sebagai pondasi tubuh dan penahan berat tubuh. Saat berjalan atau berlari, kaki berperan sebagai pengungkit untuk memajukan tubuh. Salah satu bagian penting pada kaki adalah archus.
Menurut Houglum \& Bertoti (2012), archus kaki terbagi menjadi tiga, yaitu archus longitudinal medial, archus longitudinal lateral, dan archus transversal. Berfungsi membantu kaki beradaptasi di berbagai jenis permukaan tanah, sebagai penyerap kekuatan yang diberikan ke kaki, base of support (penopang tubuh), memberikan kekuatan dan menyesuaikan keseimbangan saat berjalan serta mendistribusikan berat badan secara merata pada kaki dan menyimpan energi saat berlari (Lowth, 2016).

Salah satu kondisi gangguan muskuloskeletal pada kaki adalah flat foot atau pes planus adalah keadaan dimana archus longitudinal medial tidak membentuk lengkungan sehingga kaki 
kontak penuh dengan tanah. Flat foot dapat disebabkan karena keturunan (kongenital), kelemahan ligamen di kaki, kelemahan otot, atau ketegangan pada otot-otot ekstrinsik ankle joint (Houglum \& Bertoti, 2012).

Flat foot dapat menimbulkan berbagai macam permasalahan. Benedetti et al., (2011) mengatakan terdapat 11,3\% dari 15 orang anak usia 10-14 tahun merasakan kesulitan maupun kelelahan saat berdiri atau berjalan dalam waktu yang lama, sebanyak 54\% merasakan nyeri di area plantar dan medial hindfoot. Perubahan yang terjadi pada biomekanik tubuh memungkinkan seseorang yang menderita flat foot mudah mengalami cedera, bangunan tubuh dapat mengalami kerusakan secara keseluruhan (Ariani et al., 2014).

Menurut Boccolini et al., (2013) keseimbangan adalah kemampuan untuk menjaga center of gravity (COG) terhadap bidang tumpu (base of support) dan hasil dari kerja sistem neuromuskular sebagai respon umpan balik komponen visual, vestibular, dan somatosensoris. Terdapat dua tipe keseimbangan yaitu, keseimbangan statis dan keseimbangan dinamis. Keseimbangan statis adalah kemampuan untuk mempertahankan posisi dan sikap tetap di tempat. Sedangkan keseimbangan dinamis, adalah kekuatan untuk bertahan dan mempertahankan tubuh ketika ada pergerakan (Ma'mun, 1998 dalam Achmad, 2013).

Penelitian Nakhostin-Roohi et al., (2013) menunjukkan bahwa 50 remaja wanita berusia 14-17 tahun dengan kondisi flat foot memiliki keseimbangan statis dan dinamis yang buruk. Keseimbangan diperlukan saat melakukan aktivitas seperti berjalan, berlari, dan berdiri. Apabila seseorang memiliki keseimbangan yang rendah, maka dapat mengakibatkan rentan jatuh dan mengalami hambatan saat berjalan. Lengkung kaki atau archus yang tumbuh tidak normal menimbulkan gangguan keseimbangan, deformitas berlanjut, mudah mengalami cedera, dan rasa nyeri (Sahabuddin, 2016).

\section{METODE}

Jenis penelitian yang diambil bersifat observasional dengan metode cross-sectional. Teknik sampling yang digunakan dalam penelitian ini adalah purposive sampling. Penelitian dilakukan pada tanggal 26 dan 27 Februari 2020 di SMAN 3 Malang pada 26 responden pelajar berusia 15-18 tahun.

Instrumen penelitian yang digunakan untuk mengidentifikasi flat foot adalah Staheli Arch Index dan Chippaux Smirak Indek, sedangkan untuk mengukur keseimbangan dinamis menggunakan $Y$ Balance Test..

\section{HASIL PENELITIAN}

Karakteristik responden dikelompokkan berdasarkan usia, jenis kelamin, dan flat foot dapat dilihat pada diagram berikut.

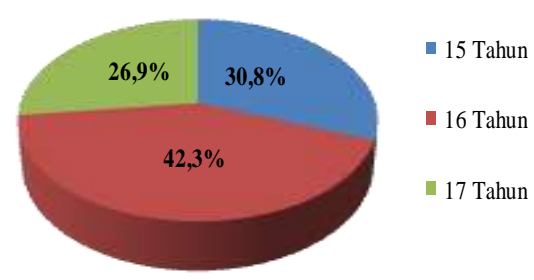

\section{Diagram 1 Karakteristik Responden Berdasarkan Usia}

Berdasarkan diagram 1, responden usia 15 tahun sebanyak 8 orang $(30,8 \%)$, usia 16 tahun sebanyak 11 orang $(42,3 \%)$, dan usia 17 tahun sebanyak 7 orang $(26,9 \%)$.

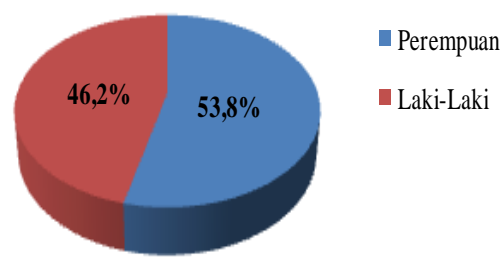

Diagram 2 Karakteristik Responden Berdasarkan Jenis Kelamin 
Berdasarkan diagram 2, responden lakilaki sebanyak 12 orang $(46,2 \%)$ dan perempuan sebanyak 14 orang $(53,8 \%)$.

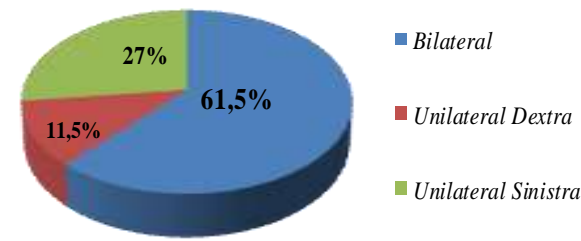

\section{Diagram 3 Karakteristik Responden Berdasarkan Kejadian Flat Foot}

Berdasarkan diagram 3, responden dengan kondisi flat foot bilateral atau flat foot di kaki kanan dan kiri sebanyak 16 orang $(61,5 \%)$, flat foot di kaki kanan (unilateral dextra) sebanyak 3 orang $(11,5 \%)$, dan flat foot di kaki kiri (unilateral sinistra) sebanyak 7 orang (27\%).

Karakteristik responden berdasarkan keseimbangan dinamis dapat dilihat pada tabel di bawah ini.

Tabel 1 Karakteristik Responden Berdasarkan Keseimbangan Dinamis

\begin{tabular}{ccc}
\hline & Kanan & Kiri \\
\cline { 2 - 3 } & Mean & Mean \\
\hline Anterior & 69,04 & 68,65 \\
Posteromedial & 76,27 & 76,35 \\
Posterolateral & 77,31 & 76,54 \\
Composite & 119,9 & 119,26 \\
\hline
\end{tabular}

Berdasarkan tabel 1, diperoleh hasil rata-rata nilai anterior kaki kanan sebesar 69,04, rata-rata nilai posteromedial kaki kanan 76,27, rata-rata nilai posterolateral kaki kanan 77,31, dan rata-rata nilai composite kaki kanan 119,9. Sedangkan pada kaki kiri, rata-rata nilai anterior sebesar 68,65, rata-rata nilai posteromedial 76,35 , rata-rata nilai posterolateral 76,54 , dan rata-rata nilai composite 119,26.
Hasil analisa data uji normalitas dan korelasi atau hubungan kejadian flat foot terhadap keseimbangan dinamis dapat dilihat pada tabel berikut.

Tabel 2 Hasil Uji Normalitas

\begin{tabular}{ccc}
\hline & $\begin{array}{c}\text { Sig. } 2 \\
\text { Tailed }\end{array}$ & $\boldsymbol{\alpha}$ \\
\hline Staheli Arch Index & 0,00 & 0,05 \\
Composite Right & 0,00 & 0,05 \\
Composite Left & 0,00 & 0,05 \\
\hline
\end{tabular}

Uji Shapiro-Wilk : Sig. 2 tailed $=$ probabilitas uji normalitas Shapiro-Wilk ; $\boldsymbol{\alpha}=$ nilai batas peluang kesalahan.

Berdasarkan tabel 2, hasil uji normalitas shapiro-wilk pada Staheli Arch Index dan Nilai Composite Y-Balance Test menunjukkan nilai significant masingmasing sebesar 0,00 . Nilai significant $<\alpha$ $(0,05)$ yang memiliki makna bahwa data dari masing-masing variabel berdistribusi tidak normal.

Kemudian, dilanjutkan dengan uji hipotesis menggunakan Uji Spearman. Hasil uji hipotesis dapat dilihat pada tabel di bawah ini

Tabel 3 Hasil Uji Spearman

\begin{tabular}{lcc}
\hline & $\begin{array}{l}\text { Sig. 2 } \\
\text { Tailed }\end{array}$ & $\begin{array}{c}\text { Correlation } \\
\text { Coefficient }\end{array}$ \\
\hline $\begin{array}{l}\text { Korelasi staheli } \\
\text { arch index dengan } \\
\text { nilai composite } \\
\text { right }\end{array}$ & 0,104 & $-0,326$ \\
\hline $\begin{array}{l}\text { Korelasi staheli } \\
\text { arch index dengan } \\
\text { nilai composite left }\end{array}$ & 0,197 & $-0,262$ \\
\hline
\end{tabular}

Uji Spearman : Sig. 2 Tailed $=$ nilai probabilitas uji statistik spearman; Correlation Coefficient $=$ kekuatan korelasi antar variabel

Uji hipotesis pada tabel 3 menunjukkan nilai significant sebesar 0,104 dan 0,197 sehingga nilai significant > 0,05 yang bermakna bahwa H0 diterima atau tidak ada hubungan kejadian flat foot terhadap keseimbangan dinamis pada pelajar di SMAN 3 Malang, serta flat foot memiliki kekuatan hubungan yang lemah dan tidak searah terhadap keseimbangan dinamis. 


\section{PEMBAHASAN}

Memiliki kemampuan beradaptasi dengan berbagai macam permukaan tanah membuat kaki menjalankan fungsinya yang kaku seperti tuas untuk mendorong tubuh ke depan saat berjalan dan berlari dengan bantuan beberapa komponen, yaitu archus longitudinal medial, plantar fascia, calcaneonavicular ligament, long dan short plantar ligament. Archus longitudinal medial menjalankan fungsinya sebagai struktur yang kaku saat berjalan dengan mekanisme arch-spring dan windlass mechanism. Ketika menjalankan kedua mekanisme tersebut, archus akan terkompresi sehingga bergerak seperti pegas karena memanjang selama fase awal sampai fase pertengahan mid-stance pada gait cycle. Kemudian, archus memendek di akhir stance phase untuk membantu pergerakan kaki saat fase push-off, inilah yang disebut arch-spring. Transisi archus dari struktur yang fleksibel menjadi kaku disebut dengan windlass mechanism plantar fascia, dimana plantar fascia juga meregang dan memendek agar archus dapat bergerak seperti pegas (Welte et al., 2018).

Pada kondisi flat foot terjadi defisiensi windlass mechanism karena plantar fascia tidak dapat menegang saat extensi metatarsophalangeal joint (Kruger et al., 2019). Sehingga kurang mampu mendorong tubuh ke depan pada saat kaki meninggalkan pijakan pada fase push-off ketika berjalan (Sahabuddin, 2016).

Otot tibialis posterior yang merupakan penyokong utama dari archus longitudinal medial, berfungsi mengontrol pronasi kaki dengan kontraksi eksentrik dan supinasi kaki dengan kontraksi konsentrik. Pronasi yang berlebihan pada flat foot terjadi karena kemampuan shock absorption (meredam kejut) menurun. Kondisi flat foot membuat plantar fascia mengalami peregangan yang berlebihan (overstretched), talonavicular joint hipermobility, peningkatan tekanan di area dorsal midfoot, dan menurunnya gerakan tendon tibialis posterior. Nyeri yang dirasakan individu yang mengalami flat foot disebabkan oleh meningkatnya stress pada metatarsophalangeal joint, otot dan tendon tibialis posterior, dan plantar fascia (Dabholkar \& Agarwal, 2020).

Otot-otot intrinsik kaki sangat berperan penting dalam menjaga stabilisasi atau keseimbangan dan memberikan dukungan serta bantuan saat kaki melakukan aktivitas (Houglum \& Bertoti, 2012).

Dalam kondisi flat foot kerja otototot intrinsik cenderung lebih keras sehingga mengakibatkan overused untuk menstabilkan archus karena hilangnya dukungan pasif dari ligamen, sehingga terjadi kelelahan kaki dan nyeri (Dabholkar \& Agarwal, 2020). Kelemahan otot-otot intrinsik kaki seperti otot abductor hallucis, flexor hallucis brevis, flexor digitorum brevis, dan otot interosseus yang bertindak sebagai stabilisator dinamis archus longitudinal medial menyebabkan kemampuannya untuk menyerap tekanan dari luar menjadi lebih rendah dan ketidakstabilan postural. Selain itu, tekanan di area plantar terpusat pada metatarsal II dan III dibandingkan dengan kaki normal ketika aktivitas dinamis seperti berjalan. Akibatnya, distribusi tekanan plantar berubah yang berujung meningkatkan risiko cedera (Arachchige et al., 2019).

Meskipun belum ditemukan alasan yang pasti mengenai individu yang mengalami flat foot memiliki keseimbangan statis dan dinamis yang buruk, kemungkinan hal tersebut bisa terjadi karena perubahan struktural dan fungsional kaki dan ketidakmampuan kaki menyerap gaya eksternal (Kim \& Kim, 2016). Kaki memiliki reseptor sensorik berupa sistem saraf di plantar fascia, ligamen, kapsul sendi, otot dan tendon di area plantar yang berfungsi sebagai elemen sensasi berjalan dan keseimbangan. Reseptor sensoris pada otot-otot intrinsik kaki dapat lebih aktif jika diberikan latihan peregangan sehingga dapat memberikan informasi 
tentang perubahan postur kaki (McKeon et al., 2015). Foot alignment yang tidak anatomis menyebabkan tekanan tambahan pada muscle spindle dan tendon talocalcaneal joint yang mengakibatkan terjadinya gangguan proprioseptif pada kaki (Arachchige et al., 2019).

Perlu diketahui bahwa instrumen untuk mengukur keseimbangan dinamis pada penelitian ini menggunakan $Y$ Balance Test yang merupakan modifikasi dari Star Excursion Balance Test (SEBT). Ketika responden melakukan tes ini dituntut untuk mencapai arah sejauh mungkin dengan mempertahankan postur tegak dan keseimbangan dengan satu kaki. Oleh karena itu, dibutuhkan kombinasi gerakan kaki (foot), pergelangan kaki (ankle), lutut (knee), dan pinggul (hip) serta memaksakan kekuatan rentang gerak sendi atau range of motion (ROM) (Dabholkar et al., 2012).

Hasil penelitian ini menyatakan bahwa tidak ada hubungan kejadian flat foot terhadap keseimbangan dinamis pada pelajar di SMAN 3 Malang. Hal ini sejalan dengan penelitian Kim et al., (2014), yang menjelaskan bahwa selama melakukan $Y$ Balance Test terjadi adaptasi kompensasi postural yang disebabkan oleh adaptasi otot karena faktor eksternal seperti integrasi visual, auditori, somatosensoris, dan proprioseptif lainnya. Didukung dengan Pozzi et al., (2015) yang mengatakan bterjadi aktivasi otot tibialis anterior dan peroneus longus sebagai mekanisme kompensasi untuk meningkatkan keseimbangan ankle joint tepatnya pada arah posteromedial.

Sehingga meskipun terdapat perbedaan morfologis kaki baik normal foot maupun flat foot, tidak ditemukan perbedaan signifikan terhadap keseimbangan dinamis karena adanya kompensasi dari otot-otot tersebut (Kumala et al., 2019). Penelitian Vakili et al., (2016) yang dilakukan pada atlet dan non-atlet menyatakan bahwa keseimbangan lebih dipengaruhi oleh kebugaran dan kinerja saraf maupun otot dibandingkan faktor biomekanik seperti postur kaki.

Gaya hidup juga dapat menjadi faktor perancu keseimbangan dan mobilitas daripada postur kaki. Jika individu sering melakukan aktivitas dengan unsur melatih kekuatan dan daya tahan (strength and endurance) ekstremitas bawah, dapat memengaruhi keseimbangan dan mobilitas terlepas dari jenis postur kaki (Said et al., 2015). Salah satu latihan penguatan yang digunakan pada kondisi flat foot adalah short feet exercise. Latihan ini menstimulasi proprioseptif di bawah kaki untuk meningkatkan stimulasi saraf afferen, sehingga meningkatkan keseimbangan dan aktivitas otot volunter (Moon et al., 2014). Faktor neural memengaruhi kekuatan otot dengan meningkatkan rekrutmen neuron, meningkatkan koordinasi motor unit serta meningkatkan aktivitas otot agonis, menurunkan aktivitas otot antagonis, dan menghambat mekanisme perlindungan otot (Listyorini et al., 2015). Indeks massa tubuh juga memengaruhi keseimbangan dinamis, Oh \& Park (2013) mengatakan bahwa individu dengan indeks massa tubuh yang tinggi cenderung memiliki penurunan kekuatan ekstremitas bawah dan keseimbangan dinamis.

\section{KESIMPULAN}

Berdasarkan hasil yang diperoleh, kesimpulan dari hasil penelitian yang berjudul Hubungan Kejadian Flat Foot Terhadap Keseimbangan Dinamis pada Pelajar di SMAN 3 Malang adalah tidak ada hubungan kejadian flat foot terhadap keseimbangan dinamis pada pelajar di SMAN 3 Malang.

\section{DAFTAR PUSTAKA}

Achmad, N. A. (2013). Pengembangan Model Pembelajaran Latihan Dasar Keseimbangan Melalui Pendekatan Permainan "Si Bolang" pada Siswa Kelas III SDN Bedono 01 Kecamatan Sayung Kabupaten Demak Tahun 
2012/2013. Semarang: Universitas Negeri Semarang.

Arachchige, K., K, S. N., Chander, H., \& Knight, A. (2019). Flatfeet: Biomechanical implications, assessment, and management. The Foot, 81-85.

Ariani, L., Wibawa, A., \& Muliarta, I. M. (2014). Aplikasi Heel Raises Exercise Dapat Meningkatkan Lengkungan Kaki Dan Keseimbangan Statis Pada AnakAnak Flat Foot Usia 4-5 Tahun Di TK Aisyiyah Bustanul Athfal 3 Denpasar. Majalah Ilmiah Fisioterapi Indonesia, Volume 3 Nomor 3.

Benedetti, M. G., Ceccarelli, F., Berti, L., Luciani, D., Catani, F., Boschi, M., et al. (2011, January 1). Diagnosis of Flexible Flatfoot in Children:A Systematic Clinical Approach. Volume 34, Issue 2.

Boccollini, G., Brazzit, A., Bonfanti, L., \& Alberti, G. (2013). Using Balance Training to Improve The Performance of Youth Basketball Players. Sport Sciences for Health, Volume 9, Issue 2, pp 37-42.

Dabholkar, A., Shah, A., \& Yardi, S. (2012). Comparison of Dynamic Balance Between Flat Feet and Normal Individuals Using Star Excursion Balance Test. Indian Journal of Physiotherapy \& Occupational Therapy Letter, Volume 6, No. 3, 33-37.

Dabholkar, T., \& Agarwal, A. (2020). Quality of Life in Adult Population with Flat Feet. International Journal of Health Sciences and Research, Volume 10 Issue 2, 193200.

Damayanti, A. E. (2016). Hubungan Citra Tubuh, Aktivitas Fisik, Dan
Pengetahuan Gizi Seimbang Dengan Status Gizi Remaja Putri. Surabaya: Universitas Airlangga.

Houglum, P. A., \& Bertoti, D. B. (2012). Brunnstrom's Clinical Kinesiology, Sixth Edition. Philadelphia: F.A.Davis Company.

Kementrian Kesehatan RI. (2017). Pusat Data dan Informasi Kementrian Kesehatan RI Situasi Kesehatan Reproduksi Remaja. Kementrian Kesehatan Republik Indonesia.

Kim, E. K., \& Kim, J. S. (2016). The Effect of Short Foot Exercises and Arch Support Insoles on Improvement in The Medial Longitudinal Arch and Dynamic Balance of Flexible Flatfoot Patients. The Journal of Physical Therapy Science, 3136-3139.

Kim, J.-a., Lim, O.-b., \& Yi, C.-h. (2014). Difference in Static and Dynamic Stability Between Flexible Flatfeet and Neutral Feet. Gait \& Posture.

Kruger, K. M., Graf, A., Flanagan, A., McHenry, B. D., Altiok, H., Smith, P. A., et al. (2018). Segmental Foot and Ankle Kinematic Differences between Rectus, Planus, and Cavus Foot Types. Journal of Biomechanics, 180-186.

Kumala, M. S., Tinduh, D., \& Poerwandari, D. (2019). Comparison of Lower Extremities Physical Performance on Male Young Adult Athletes with Normal Foot and Flatfoot. Surabaya Physiscal Medicine and Rehabilitation Journal, Ediiton 1 Volume 1, 6-13.

Listyorini, I., Shanti, M., \& Prabowo, T. (2015). Effectiveness in Dynamic Balance: A Comparison between Foot Muscle Strengthening Using Elastic Band and Without Elastic 
Band in Children Aged 8-12 with Flexible Flatfeet. International Journal of Integrated Health Sciences, Volume 3 No.1, 26-32.

Lowth, M. (2016, January 19). Pes Planus : Orthopaedics and Sports Medicine. Dipetik February 12, 2020, dari Orthopaedics and Sports Medicine: patient.info/doctor/pesplanus-flat-feet

McKeon, P. O., Hertel, J., Bramble, D., \& Davis, I. (2014). The Foot Core System; A New Paradigm for Understanding Intrinsic Foot Muscle Function. British Journal of Sports Medicine, 1-9.

Moon, D.-C., Kim, K., \& Lee, S.-K. (2014). Immediate Effect of Shortfoot Exercise on Dynamic Balance of Subjects with Excessively Pronated Feet. Journal of Physical Therapy Science, Volume 26 117119.

Nakhostin-Roohi, B., Hedayati, S., \& Aghayari, A. (2013). The Effect of Fleible Flat-Footedness on Selected Physical Fitness Factors in Female Students Aged 14 to 17 Years. Journal of Human Sport and Exercise, Volume 8, No. 3, pp. 788-796.

Oh, J.-s., \& Park, J.-h. (2013). An Analysis of Factors Affecting the Dynamic Balance of The Elderly. International Journal of Digital Content Technology and its Applications (JDCTA), Volume 7 , No. 12, 201-209.

Pozzi, F., Moffat, M., \& Gutierrez, G. (2015). Neuromuscular Control During Performance of A Dynamic Balance Task In Subjects With and Without Ankle Instability. The International Journal of Sports Physical Therapy, Volume 10 No. 4, 520-529.
Sahabuddin, H. (2016). Hubungan Antara Flat Foot Dengan Keseimbangan Dinamis Pada Murid TK Sulawesi Kota Makassar. Makassar: Universitas Hasanuddin.

Said, A. M., Manaf, H., Bukry, S. A., \& Justine, M. (2015). Mobility and Balance and Their Correlation with Physiological Factors in Elderly with Different Foot Postures. BioMed Research International.

Vakili, M., Hezar, N. G., \& Ebrahimi, B. (2016). Relationship Between Foot Posture and Static and Dynamic Balance in Athlete and NonAthlete Girls. Journal Sport Biomechanic Islamic Azard University, Volume 2 No.1, 15-25.

Welte, L., Kelly, L. A., Licthwark, G. A., \& Rainbow, M. J. (2018). Influence of The Windlass Mechanism on Arch-Spring Mechanics During Dynamic Foot Arch Deformation. Journal of The Royal Society. 